\title{
Carbon fiber from natural biopolymer Bombyx mori silk fibroin

\author{
with iodine treatment
}

Md. Majibur Rahman Khan", Yasuo Gotoh, Hideaki Morikawa, Mikihiko Miura, Yoshie Fujimori and Masanobu Nagura

Faculty of Textile Science and Technology, Shinshu University, Tokida 3-15-1, Ueda, Nagano 386-8567, Japan

${ }^{*}$ Corresponding author. Tel: +81-268-21-5366, Fax: +81-268-21-5454.

E-mail address: ygotohy@shinshu-u.ac.jp

\begin{abstract}
Carbon fibers were prepared from silk fibers after an iodine treatment and the carbon yield, fiber morphology, structure and mechanical properties were investigated. A single or multi step carbonization process was used for the preparation. In the single step process, silk fibroin (SF) fibers were heated from 25 to $800{ }^{\circ} \mathrm{C}$ with a heating rate of $5{ }^{\circ} \mathrm{C}$ min-1 under Ar atmosphere. However, the carbon fiber obtained was partially melted and was too fragile to handle. For better performance, SF fibers were treated with iodine vapor at $100{ }^{\circ} \mathrm{C}$ for $12 \mathrm{~h}$ and untreated and iodinated SF fibers were heated from 25 to $800{ }^{\circ} \mathrm{C}$ by a multi step carbonization process, which was defined based on the optimum thermal degradation rate of silk. In this multi step process, the carbon fibers obtained from iodinated SF were structurally intact and stable in appearance, and the carbon yield achieved was ca. $36 \mathrm{wt} \%$, much higher than the value for untreated SF. X-ray diffraction, Raman spectroscopy and transmission electron microscopic observation revealed that the obtained carbon fibers from both untreated and iodinated SF were a basically amorphous structure. The strength of carbon fibers prepared from
\end{abstract}


iodinated SF using the multi step carbonization was considerably increased compared to that of untreated SF. According to viscoelastic measurement, by heating above $280{ }^{\circ} \mathrm{C}$ the iodine introduced intermolecular cross-linking of the SF, and its melt flow was inhibited which produced a higher yield and better performance of the carbon fiber.

Keywords: carbon fibers; carbonization; scanning electron microscopy; carbon yield; mechanical properties.

\section{Introduction}

Silk fibroin (SF), an extensively studied natural biopolymer is commonly used as a textile fiber. It is produced by different silkworm species, and the most important being is the domesticated mulberry worm Bombyx mori. The chemical structure of Bombyx mori SF molecule is characterized by the presence of three amino acids, glycine (45\%), alanine (30\%) and serine (12\%) in a roughly 3:2:1 ratio and the sequence is dominated by [Gly-Ala-Gly-Ala-Gly-Ser] $]_{\mathrm{n}}$. Moreover, SF chain also contains amino acids with bulky and polar side chains, in particular tyrosine, valine and acidic amino acids.

In the development of new materials from SF, the researches concerning the carbonization of silk are involved. Heretofore, thermal decomposition behaviors of silk materials have been reported, but the majorities are for the pyrolysis behavior of $300{ }^{\circ} \mathrm{C}$ or less, which corresponds to an initial process of the carbonization [1-12]. Recently, carbonization behavior of silk at higher temperature has been investigated intensely. The carbonization behavior at $800{ }^{\circ} \mathrm{C}$ of mulberry silk, tussah silk and amino acid component have been investigated and it has observed that from the silk, non-graphitizing carbon could be obtained with a carbon yield of $30 \%$, which was much higher than the value measured for the cellulose based carbon [13].

Carbonized silk materials exhibit highly anti bacterial property and it possess multiple numbers of dimples on its surfaces by heating and are used as supports for catalysts, e.g. fine particle of platinum, titanium oxide, and metal phthalocyanine, which are suitable for adsorption and decomposition of harmful substances and for deodorization [14]. By utilizing the antibacterial properties of carbonized silk, many products have been developed or proposed to develop in biomedical field, such as, 
carbonized silk products for skin external preparations [15], wound dressing [16], hazardous substance decomposer [17], mask with antibacterial material [18], carbonized cocoons for gas adsorbent [19], etc. Carbonized silk materials are also used in other fields, such as, to produce fuel cell [20], electric double layer capacitor [21], electromagnetic shields [22].

Recent researches reveal that iodine is a good stabilizing agent for producing higher yield pitch carbon. It has been pointed out that iodine acts to promote dehydrogenative polymerization during carbonization and leads to the extremely high carbon yield of coal tar pitch $[23,24]$. In addition, carbon yield for some kinds of polymers such as polyacrylonitrile and poly(vinyl alcohol) have been considerably enhanced by carbonization with iodine treatment [25,26]. However, the applying of the iodine treatment to SF has not been reported. Beforetime it has been reported that SF absorbs iodine and the structure and physical properties are significantly influenced [27-31]. Thus, it is worth investigating the influence of iodine treatment on carbon yield of SF by carbonization.

In this study, we reported the carbonization behavior of iodinated SF, and evaluated the carbon yield, fiber morphology, fine structure and the mechanical properties.

\section{Experimental}

\subsection{Materials}

Bombyx mori degummed SF fiber used in this experiment was provided by North Eastern Industrial Research Center, Shiga prefecture, Japan. To remove impurity, Soxlhet extraction was conducted by using methanol until SF became completely white.

\subsection{Iodine treatment}

The iodine treatment of SF fiber was carried out as follows: an adequate quantity of SF fiber was enclosed with abundant iodine in a small test tube in a glass vessel. After sealing the glass vessel, it was placed in an oven heated at $100{ }^{\circ} \mathrm{C}$ where iodine was vaporized and kept for several periods. The color of SF fiber turned to dark brown by 
the treatment. The iodine sorption content was calculated by measuring the weight change of the SF fibers before and after the iodine treatment.

\subsection{Carbonization}

Iodinated SF fibers were heated to $800{ }^{\circ} \mathrm{C}$ under controlled heating schedules in a tubular furnace under an Ar flow. The heating schedule was an important factor to determine quality of carbon fibers obtained from SF fibers. The carbonization process has been described in details as follows:

In order to produce carbon fibers and ceramic materials with good mechanical properties, the carbonization condition is very important. For example, carbon fiber was prepared from untreated SF fiber by heating from 25 to $800{ }^{\circ} \mathrm{C}$ with a constant heating rate of $5{ }^{\circ} \mathrm{C} \mathrm{min}^{-1}$ under an Ar gas flow, (called as 'single step carbonization' in this study), and consequently, the carbon fiber was very weak and was too fragile to handle. Thus, milder carbonization schedule is necessary for higher performance of silk based carbon fibers, and dynamic TGA measurement using untreated SF fiber was carried out by $\mathrm{CRC}$ mode at $-0.001 \mathrm{wt} \% / \mathrm{sec}$ of weight reduction rate to determine heating schedule for carbonization. Fig. 1 shows the dynamic TGA result of untreated SF fiber. The solid and broken lines indicate heating temperature profile and TG curve, respectively. According to this result, the heating schedule for carbonization (called as 'multi step carbonization' in this study) was then determined as shown Fig. 2. By using multi step carbonization, the quality of carbon fiber obtained was clearly enhanced, which was possible to handle and used for mechanical measurement. So we considered only the fibers that obtained by multi step process for comparing carbon yield percentage in different iodine treatment times and as well as for measuring the structure and mechanical properties.

\subsection{Measurements}

Thermogravimetric analysis (TGA) was carried out from room temperature to $800{ }^{\circ} \mathrm{C}$ at a heating rate of $5{ }^{\circ} \mathrm{C}$ with Rigaku Thermo plus II TG 8120 under an Ar atmosphere. Dynamic TGA was performed using constant reaction control (CRC) mode to $800^{\circ} \mathrm{C}$ at 
$-0.001 \mathrm{wt} \% / \mathrm{sec}$ of constant weight reduction rate.

The fiber morphology was examined with a Hitachi S-2380N, Scanning electron microscope (SEM) at $15 \mathrm{kV}$ of acceleration voltage.

Raman spectroscopy was measured by S. T. Japan, Inc. HoloLab-5000, equipped with a MK-II filtered probe head using Nd: YAG (Yttrium Aluminum Garnet) laser beam of $532 \mathrm{~nm}$ generated at $50 \mathrm{~mW}$. The measurement was carried out under the conditions of resolution of $2.5 \mathrm{~cm}^{-1}$ with $10 \mathrm{~s}$ exposure 10 times.

Wide angle X-ray diffraction (WAXD) profile was obtained by a Rigaku Rotorflex RU-200B diffractometer using Ni-filtered $\mathrm{CuK}_{\alpha}$ radiation generated at $40 \mathrm{kV}$ and 150 $\mathrm{mA}$.

Transmission electron microscopic (TEM) observation was conducted at an acceleration voltage of $200 \mathrm{kV}$ using JEOL JEM-2010 instrument.

The elemental analysis was performed on a Parkin-Elmer 2400 II analyzer using the normal procedure.

The tensile properties were measured with a Tensilon Model RTC 1250A, (Orientec Corporation), Japan using standard technique at $22{ }^{\circ} \mathrm{C}$ and $65 \% \mathrm{RH}$ at a gauge length of $40 \mathrm{~mm}$ and strain rate of $40 \mathrm{~mm} / \mathrm{min}$.

Dynamic mechanical thermal analysis (DMTA) was measured from room temperature to $400{ }^{\circ} \mathrm{C}$ in air by using an ITK Co. DVA-225 at the stretching mode of 10 $\mathrm{Hz}$ and a heating rate of $10^{\circ} \mathrm{C} \mathrm{min}^{-1}$.

\section{Results and discussion}

\subsection{Iodine sorption and carbon yield}

Fig. 3 shows Raman spectrum of iodinated SF fiber. Two strong peaks at 112 and 168 $\mathrm{cm}^{-1}$ are assigned to the $\mathrm{I}_{3}^{-}$and $\mathrm{I}_{5}^{-}$vibration, respectively [32,33]. Therefore, this result suggests that at least two types of polyiodine ions exist in SF fiber.

The iodine sorption percentage of SF fibers is shown as a function of iodine treatment time in Fig. 4. The weight of the SF fibers increased monotonously with iodine treatment time. After $12 \mathrm{~h}$, the iodine content was achieved by ca. $42 \mathrm{wt} \%$ by introduction of iodine component into the fibroin. Then, the trend of weight increasing 
was very slow and it became almost saturated with ca. $52 \mathrm{wt} \%$ iodine content after $24 \mathrm{~h}$.

In producing carbon materials from polymeric precursors, higher weight loses during carbonization generally results in high cost, thus "yield" is an important aspect for carbon fiber production. The relationship between carbon yield and iodine treatment time in multi step carbonization process is shown in Fig. 5. In case of untreated SF, the carbon yield was $29 \mathrm{wt} \%$. The carbon yields considerably increased and reached up to ca. $36 \mathrm{wt} \%$ as a function of iodine treatment for $12 \mathrm{~h}$. After $12 \mathrm{~h}$, the yield gradually decreased though iodine content increased. It may causes due to the presence of excess iodine ions in SF molecules. So we used only $12 \mathrm{~h}$ treated specimen for experiments. It was conformed that iodine could not detected in the specimen after carbonization at $800{ }^{\circ} \mathrm{C}$. Considering these results, iodine treatment seems an effective process to increase carbon yield of SF fibers.

Thermogravimetric analysis was carried out to make clear the carbonization behavior of the specimen. Fig. 6 shows TGA curves of untreated and iodinated SF fibers. The weight percent in the figure was calculated from the original specimen. For untreated specimen, there was no weight change up to $150{ }^{\circ} \mathrm{C}$ and drastically weight loss was marked by a sharp decrease in weight beginning at $250{ }^{\circ} \mathrm{C}$. This is associated with the degradation of side chain groups of amino acid residues as well as the cleavage of peptide bonds [34]. The yield obtained at $800{ }^{\circ} \mathrm{C}$ for untreated SF was about ca. $29 \mathrm{wt} \%$ in single step heating condition.

On the other hand, the carbonization behavior of iodinated SF fiber is different from that of untreated one. For iodinated specimen, the abrupt weight decrease was detected from 110 to $400{ }^{\circ} \mathrm{C}$. This is related to not only degradation of SF, but also vaporization of the iodine component in the specimen, because of ca. $42 \mathrm{wt} \%$ of polyiodine ions are included in the specimen, and evaporation of iodine component was confirmed during the TG measurement. The yield obtained at $800{ }^{\circ} \mathrm{C}$ for iodinated SF was about ca. $37 \mathrm{wt} \%$ in dynamic heating condition. The obtained higher yield from iodinated SF, would be related to the intermolecular cross-linking of SF by iodination, which causes inhibition of volatile component containing carbon from SF during heating and lead to higher carbon yield. 


\subsection{Fiber morphology}

Morphological changes induced by carbonization to $800{ }^{\circ} \mathrm{C}$ of untreated and iodinated SF fibers were studied by SEM. The longitudinal micrographs are shown in Fig. 7. The morphology of untreated SF fibers was greatly influenced by single step carbonization. The fiber surfaces appeared swollen, partially melted and there was dispersion of thickness [Fig. 7(a)]. This is originated from much defect formed in the specimen due to rapid thermal decomposition of SF molecule. This result was consistent with the report of Nishikawa et al [13].

It is well known that the surface of degummed SF fibers is highly smooth, showing only very fine longitudinal striation attributable to the fibrillar structure of the fiber [35]. In multi step carbonization, although the morphology of carbon fibers obtained from untreated SF was considerably improved, but it appeared till in swell condition, dispersion in thickness and rough in appearance [Fig. 7(b)]. On the contrary, the surface of carbon fibers prepared from iodinated SF became more plain and smooth [Fig. 7(c)]. From the cross sectional SEM images of the carbon fibers prepared by multi step carbonization [Fig. 8(a,b)], it is observed that there was no outstanding crack and the fibers posses a dense inner structure. In particular, the fiber from iodinated SF was remains intact. These results are not only related to milder carbonization process which prevents the rapid degradation of SF but also to the formation of the cross-linking between the adjacent SF molecules in presence of polyiodine ions $\left(\mathrm{I}_{3}^{-}, \mathrm{I}_{5}^{-}\right)$during heating.

\subsection{Structural characteristics}

To analyze the structure of the carbon fibers, measurements of XRD, Raman spectra, and TEM observation were carried out. Fig. 9 shows WAXD profiles of the carbon fibers from untreated and iodinated SF by the multi step carbonization. Only a broad peak exhibits at $2 \theta=$ ca. $24.0^{\circ}$ for both the carbons, which indicates the lack of crystalline structure. Fig. 10 shows the Raman spectra for the same samples with those in Fig.9. For the both carbons, two major broad peaks, one at $1369 \mathrm{~cm}^{-1}$ for D band and another at $1589 \mathrm{~cm}^{-1}$ for $\mathrm{G}$ band, respectively, appear in the observed results plotted 
with gray closed circles. Black broken and solid lines represent the deconvoluted and total curves, respectively, which were fitted by Gaussian function. The peak position, the peak full-width at half-maximum (FWHM) and the integrated intensity ratio of the two peaks $\left(I_{\mathrm{G}} / I_{\mathrm{D}}\right)$ obtained from the Gaussian fittings are summarized in Table 1. The spectrum of each sample is broad and is similar to a pattern of diamond-like carbon, which shows the low crystallinity and mixture of $\mathrm{sp} 2$ and $\mathrm{sp} 3$ carbons. The intensity ratio $I_{\mathrm{G}} / I_{\mathrm{D}}$ of the carbon fibers from iodinated SF is somewhat higher than that of the carbon from untreated one, but the difference in spectra and FWHM are not obviously observed, therefore, the carbon structures of the two fibers are almost same. Fig. 11 shows the TEM images of carbon fibers from untreated and iodinated SF by the multi step carbonization. Both the carbon fibers exhibit basically amorphous structure and no crystal texture, but curvy layered structure with disordering is contained in some part shown by an arrow. Fig. 12 shows the result of elemental analysis for carbon fibers from untreated and iodinated SF by multi step carbonization. This result shows the low carbon content, and high hydrogen, nitrogen and oxygen contents for carbon fiber. This may be related to antibacterial property of SF-derived carbon material. However, the composition for each sample is almost consistent with each other. Therefore, from structural analyses, the iodine treatment does not affect structure of the carbon fiber in this study, and only controls the thermal degradation behavior of SF.

\subsection{Mechanical properties}

It is worth noting that mechanical properties, particularly tensile strength and elongation at break, are the most important factors for evaluating the performance of fibers for proper applications. The tensile strength was evaluated by the load-elongation curves, in which the maximum strength of the fiber corresponds to the point where the carbon fibers break. Fig. 13 illustrates the load-elongation curves of carbon fibers prepared from untreated and iodinated SF by multi step carbonization. The average strength and elongation of carbon fibers prepared from untreated SF was 8.2 gf and 0.5 $\mathrm{mm}$ respectively. On the other hand, carbon fiber prepared from iodinated SF was shown better mechanical performances. The average value of strength and elongation of carbon fibers prepared from iodinated SF were increased to $12.6 \mathrm{gf}$ and $0.7 \mathrm{~mm}$ 
respectively. The higher strength of carbon fibers should be related to the cross-linking between adjacent SF molecules in the presence of polyiodine ions $\left(\mathrm{I}_{3}^{-}, \mathrm{I}_{5}{ }^{-}\right)$.

As an evidence of cross-linking of SF, DMTA measurement has been carried out.

\subsection{Influence of iodination on SF during carbonization}

The temperature dependence of storage modulus (E') curve of untreated and iodinated SF fiber is shown in Fig. 14. For untreated SF, the value of E' slightly increased with temperature up to $70{ }^{\circ} \mathrm{C}$ owing to evaporation of water contained in the fiber. And then, E' once remained constant, followed by the decrease above $170{ }^{\circ} \mathrm{C}$. Finally, E' exhibits a sharp fall around $260{ }^{\circ} \mathrm{C}$ due to the melting of the crystalline regions, which brings about breaking of SF fiber. On the other hand, iodination remarkably influences molecular motion of SF fibers. The thermal movement of fibroin molecules became evident from relatively low temperature, starting from about $50{ }^{\circ} \mathrm{C}$ and the onset temperature of the first fall at ca. $135{ }^{\circ} \mathrm{C}$ is lower than that of the original SF seen around $170{ }^{\circ} \mathrm{C}$. On the basis of DSC measurements of pure SF, it has been pointed out that the glass transition temperature is located at around $173{ }^{\circ} \mathrm{C}$ [11]. The above behavior of E' suggests that the glass transition temperature shifted to lower values by the presence of polyiodine ions in SF. The iodine introduction makes SF molecules easier to move and brings about softening of SF fiber (lowering of E'). Above $280{ }^{\circ} \mathrm{C}$, the iodinated SF shows that E' (i.e. the stiffness) is increased, which implies the formation of intermolecular cross-linking accompanied by the hardening of the sample. The intermolecular cross-linking of SF chains represses volatilization of carbon component in SF during the carbonization process and leads the higher carbon yield. The mechanism of cross-linking by iodination has not been clarified at this time, however, strong oxidizing property of iodine may generate reactive sites in SF chains and then cross-linking points are produced.

\section{Conclusions}

Carbon fibers were produced from natural biopolymer, Bombyx mori SF fibers treated with iodine vapor at $100{ }^{\circ} \mathrm{C}$ for $12 \mathrm{~h}$. The carbonization process was carried out by 
heating to $800{ }^{\circ} \mathrm{C}$ in $\mathrm{Ar}$ atmosphere at a single step carbonization process (constant heating rate of $5{ }^{\circ} \mathrm{C} \mathrm{min}^{-1}$ ) or a multi-step carbonization process. The multi-step process was conducted at a nearly constant decomposition rate of silk in order to inhibit the rapidly thermal decomposition, which was determined by the measurement of dynamic TGA using untreated SF. In the case of single step process, the obtained carbon fiber was fragile and was difficult to handle. On the other hand, both strength and the carbon yield of the carbon fibers prepared under multi-step heating were considerably increased. The highest carbon yield (ca. 36wt\%) was achieved from iodinated SF fibers under multi-step process ( $c f$. ca. $29 \mathrm{wt} \%$ of carbon yield for untreated SF). WAXD, Raman spectroscopy and TEM observation suggested that the obtained carbon fibers from both untreated and iodinated SF were a basically amorphous structure. DMTA measurement showed that with heating above $280{ }^{\circ} \mathrm{C}$ the iodine component introduced intermolecular cross-linking of SF and the melt flow of the SF was inhibited, which enhances higher carbon yield and better performance of silk based carbon fiber.

\section{Acknowledgements}

This work was supported by The 21st Century COE Program and Grant-in-Aid for Scientific Research program by the Ministry of Education, Science, Sports and Culture of Japan. The authors wish to express their thanks to the North Eastern Industrial Research Center, Shiga prefecture, Japan, for kindly supplying degummed SF fibers. The authors gratefully thank to Professor Fujio Okino, Dr. Yoshiyuki Hattori and Mr. Hisatoshi Koshikawa, Faculty of Textile Science and Technology, Shinshu University, Japan for their help of TEM measurements.

\section{References}

[1] Koide N. Pirolytic Behavior of silk treated with $S_{n}$-Complex. Sen'I Gakkaishi 1970; 26: 53-65.

[2] Koide N. Studies on the pyrolyzed products of silk fibroin: (i) On the ketonic acid and ketone. J Seric Sci Jpn 1971; 40: 387-90.

[3] Tsukada M, Ketone type carbonyl radicals produced in 
poly-O-benzyl-L-serine by thermal oxidation. J Seric Sci Jpn 1982; 51(3): 198-202.

[4] Tsukada M, Nagura M, Ishikawa H. Relationship between the fine structure of silk sericin and its thermal decomposition. J Seric Sci Jpn 1985; 54(1): 43-47.

[5] Zhang H, Magoshi J, Magoshi Y, Yoshida H, Chen JY, Saiki K. Inorganic composition and thermal properties of cocoon fiber. Int J Soc Mater Eng Resour 2002; 10(1): 113-16.

[6] Cunniff PM, Fossey SA, Auerbach MA, Song JW, Kaplon DL, Adams WW, et al. Mechanical and thermal properties of dragline silk from the spider Nephila clavipes. Polym Adv Technol 2003; 5: 401-10.

[7] Zhang H, Magoshi J, Becker M, Chen JY, Matsunaga R. Thermal properties of Bombyx mori silk fibers. J Appl Polym Sci 2002; 86: 1817-20.

[8] Magoshi J, Nakamura S. Physical properties and structure of silk. Glass Transition and crystallization of silk fibroin. J Appl Polym Sci 1975; 19: 1013-15.

[9] Tsukada M, Freddi G, Nagura M, Ishikawa H, Kasai N. Structural changes of silk fibers induced by heat treatment. J Appl Polym Sci 1992; 46: 1945-53.

[10] Nakamura S, Saegusa Y, Yamaguchi Y, Magoshi J, Kamiyama S. Physical properties and structure of silk. Glass Transition temperature of wild silk fibroins. J Appl Polym Sci 1986; 31: 955-56.

[11] Magoshi J, Magoshi N, Nakamura S, Kasai N, Kakudo M. Physical properties and structure of silk. V. Thermal behavior of silk fibroin in the random-coil conformation. J Polym Sci Part B 1977; 15: 1675-83.

[12] Rusakov NG, Petrov E I. Carbonization of silk wastes. Shelk 1938, 8(No. 6), 26-9.

[13] Nishikawa G, Kawahara Y, Shioya M, Kimura T. Carbonization Behavior of Silk. Sen'I Gakkaishi 2004; 60(4): 105-11.

[14] Hashizume H, Shimizu M, Yahata T, Endo M. Carbonized silk with dimpled surfaces for antibacterial materials, catalyst supports, etc. Patent 
application (in Japanese), Jpn. Kokai Tokkyo Koho JP 2005112667, 2005.

[15] Hashizume H. Skin external preparations containing fired silk products and fibroin and/or sericin. Patent application (in Japanese), Jpn. Kokai Tokkyo Koho JP 2006083143, 2006.

[16] Tanaka M, Shimizu M. Wound dressings comprising fired silk products. Patent application (in Japanese), PCT Int. Appl. WO 2006033196, 2006.

[17] Hashizume H, Shimizu M, Yawata T, Kimura M. Hazardous substance decomposer containing calcined silk and production process. Patent application (in Japanese), PCT Int. Appl. WO 2005007287, 2005.

[18] Hashizume H, Shimizu M, Yawata T, Kimura M. Silk firing products, antibacterial materials using them and process for producing silk firing products. Patent application (in Japanese), PCT Int. Appl. WO $2005007947,2005$.

[19] Chiaki T, Kojima A, Kamiishi Y. Carbonized cocoons for gas adsorbent and production method thereof. Patent application (in Japanese), Jpn. Kokai Tokkyo Koho JP 2005273077, 2005.

[20] Hashizume H, Shimizu M, Yawata T. Fuel cell, electrode material for fuel cell and method for producing same. Patent application (in Japanese), PCT Int. Appl. WO 2005008815, 2005.

[21] Miyashita M, Iwasaki T, Shimizu M. Electric double layer capacitor. Patent application (in Japanese), Jpn. Kokai Tokkyo Koho JP 2006100798, 2006.

[22] Iwasaki T, Endo M. Baked silk carbon material for electromagnetic shield. Patent application (in Japanese), Jpn. Kokai Tokkyo Koho JP 2006080174, 2006.

[23] Miyajima N, Akatsu T, Ikoma T, Ito O, Rand B, Tanabe Y, et al. A role of charge transfer complex with iodine in the modification of coal tar pitch. Carbon 2000; 38 (13): 1931-38.

[24] Kajiura H, Tanabe Y, Yasuda E. Carbonization and graphitisation behaviors of iodine treated coal tar pitch. Carbon 1997; 35 (2): 169-74.

[25] Ito T, Sadanobu, J. Preparation method of polyacrylonitrile-type carbonized materials. Patent application (in Japanese), Jpn. Kokai Tokkyo 
Koho JP 2002155428, 2002.

[26] Mukuruma S, Oki H, Shiotani M, Yamashita J. Manufacture of carbon fibers from poly(vinyl alc.)-type fibers in high yield and reduced fiber-to-fiber adhesion by halogenating the fibers in the stretched state and heat-treating the fibers and,carbon fibers and activated carbon fibers therefrom. Patent application (in Japanese), Jpn. Kokai Tokkyo Koho JP $2004339627,2004$.

[27] Khan MMR, Gotoh Y, Miura M, Morikawa H, Nagura M. Influence of iodine treatment on the structure and physical properties of Bombyx mori silk fibroin. J Polym Sci Part B: Polym Phys, in review.

[28] Friedrich-Freksa H, Kratky O, Sekora A. Occurrence of new x-ray interferences by introduction of iodine into silk fibroin of the Bombyx mori type. Naturwissenschaften 1944; 32: 78.

[29] Lecus H. The action of iodine upon tussah silk. Angew Chem 1934; 47: 779-82.

[30] Takahashi T. Studies on natural silk. I. Iodine-absorbing power of silk fibroin. J Soc Chem Ind Japan 1928; 31: 152-55.

[31] Raymond M, Rosalind R Pitt. The iodination of silk fibroin. Biochimica et Biophysica Acta 1948; 2: 223-25.

[32] Parrett FW, Taylor NJ. Spectroscopic studies on some polyhalide ions. J Inorg Nucl Chem 1970; 32(7): 2458-61.

[33] Mizuno M, Tanaka J, Harada I. Electronic spectra and structures of polyiodide chain complexes. J Phys Chem 1981; 85(13): 1789-94.

[34] Freddi G, Tsukada M, Beretta S. Structure and physical properties of silk fibroin/polyacrylamide blend films. J Appl Polym Sci 1999; 71: 1563-71.

[35] Arai T, Freddi G, Innocenti R, Tsukada M. Biodegradation of Bombyx mori Silk Fibroin Fibers and Films. J Appl Polym Sci 2004; 91: 2383-90. 


\section{LIST OF FIGURES AND TABLES}

Fig. 1. Dynamic TGA and temperature profiles of untreated SF at $-0.001 \% / \mathrm{sec}$ weight reduction rate under CRC mode.

Fig. 2. Heating schedules for multi step carbonization of untreated and iodinated SF.

Fig. 3. Raman spectrum of iodinated SF fiber.

Fig. 4. Iodine sorption percentage of SF fiber at different iodine treatment times.

Fig. 5. Relationship between iodine treatment time and the yield of carbonized SF fiber according to multi step carbonization. The dotted line indicates the yield (29\%) of untreated SF fiber.

Fig. 6. TGA curves of SF fiber: (a) untreated specimen, measured at a heating rate of $5{ }^{\circ} \mathrm{C}$ in single step heating condition: (b) iodinated specimen, measured at $-0.001 \% / \mathrm{sec}$ weight reduction rate under CRC mode in dynamic condition.

Fig. 7. Longitudinal SEM images of carbon fibers prepared from untreated and iodinated SF: (a) untreated specimen heated by single step carbonization; (b) untreated specimen heated by multi step carbonization; (c) iodinated specimen heated by multi step carbonization.

Fig. 8. Cross-sectional SEM images of carbon fibers prepared by multi step carbonization from untreated and iodinated SF: (a) untreated specimen, (b) iodinated specimen.

Fig. 9. Equatorial WAXD profiles of carbon fibers prepared by multi step carbonization from untreated and iodinated SF: (a) untreated specimen, (b) iodinated specimen.

Fig. 10. Raman spectra of carbon fibers prepared by multi step carbonization from untreated and iodinated SF: (a) untreated specimen, (b) iodinated specimen.

Fig. 11. TEM images of carbon fibers prepared by multi step carbonization from untreated and iodinated SF: (a) untreated specimen, (b) iodinated specimen.

Fig. 12. Elemental composition of carbon fibers prepared by multi step carbonization from untreated and iodinated SF: (a) untreated specimen, (b) iodinated specimen.

Fig. 13. Load-elongation curves of carbon fibers prepared by multi step carbonization from untreated and iodinated SF: (a) untreated specimen, (b) iodinated specimen.

Fig. 14. Temperature dependence of storage modulus for untreated (dotted line) and iodinated (solid line) SF fiber. 
Table 1. Structural parameters of carbon fibers prepared by multi step carbonization from untreated and iodinated SF determined by Raman spectroscopy. 


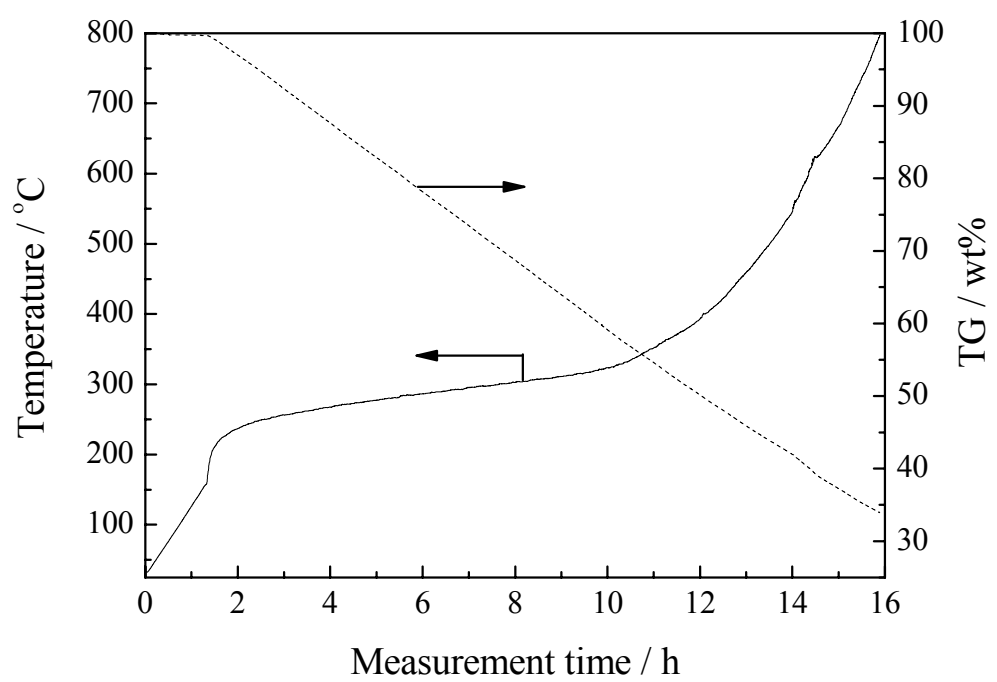

Fig. 1. Dynamic TGA and temperature profiles of untreated SF at $-0.001 \% / \mathrm{sec}$ weight reduction rate under CRC mode.

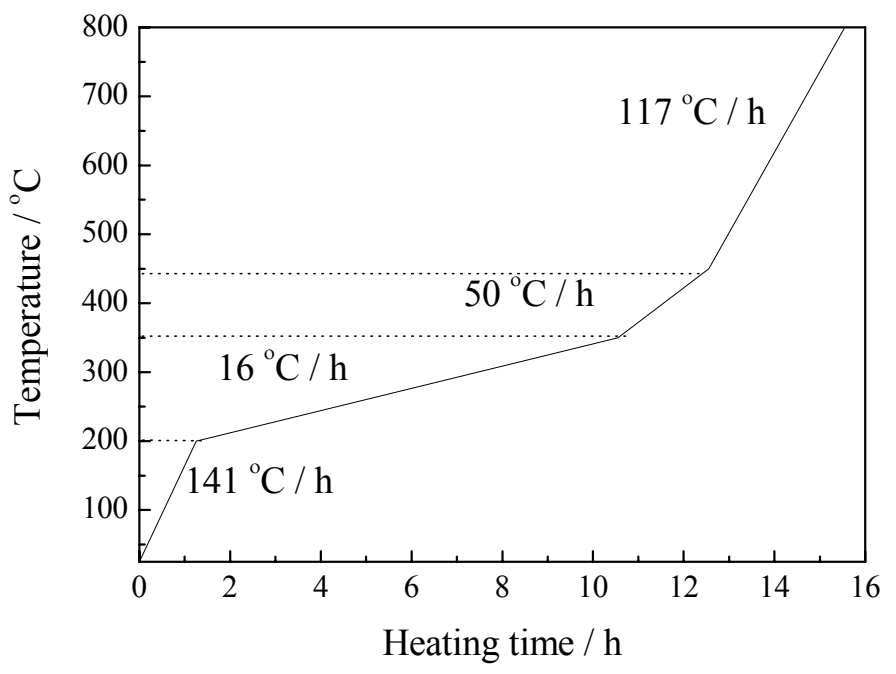

Fig. 2. Heating schedules for multi step carbonization of untreated and iodinated SF. 


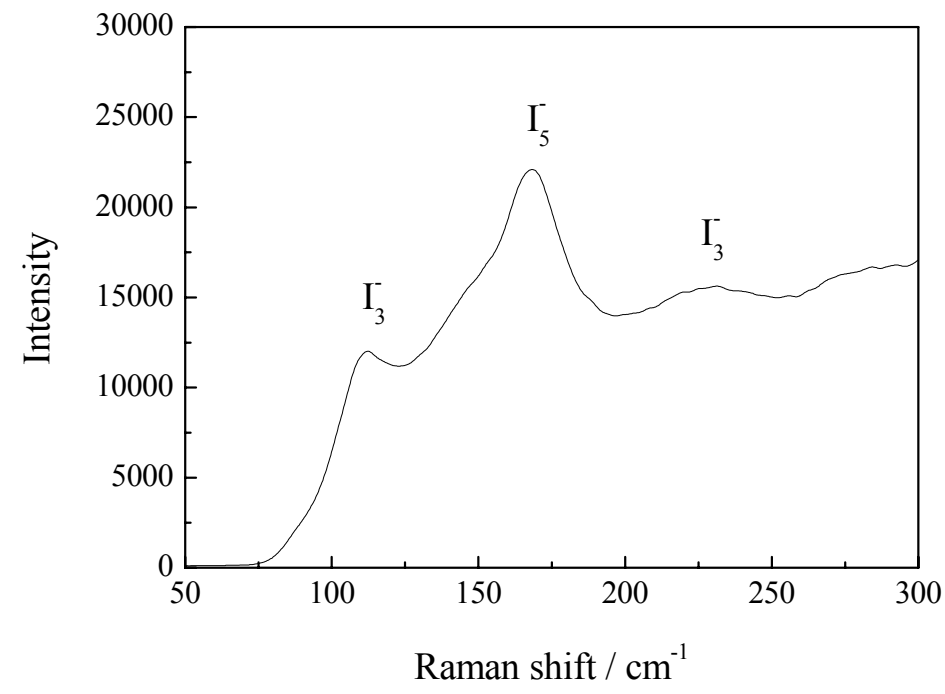

Fig. 3. Raman spectrum of iodinated SF fiber.

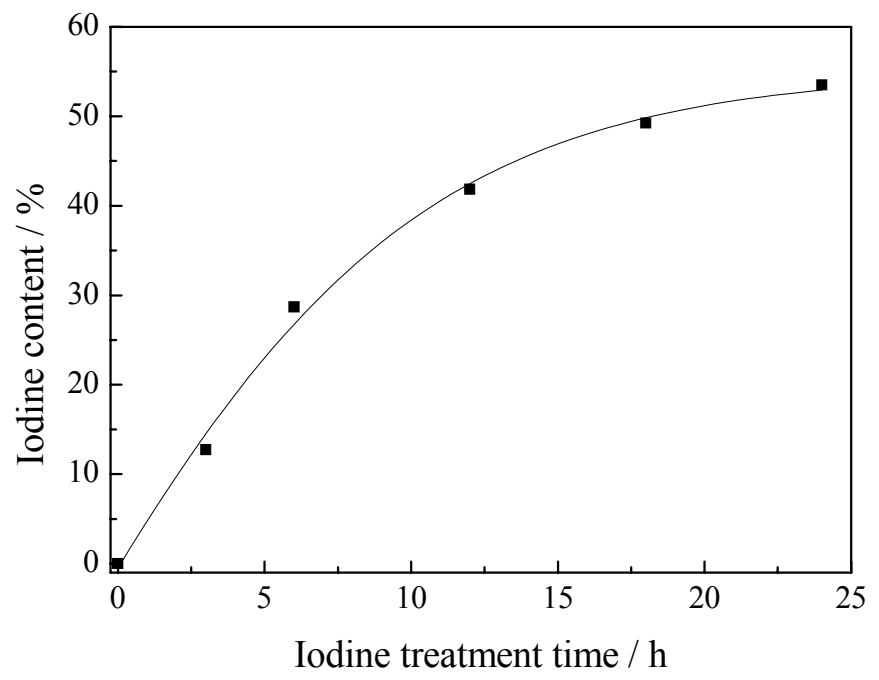

Fig. 4. Iodine sorption percentage of SF fiber at different iodine treatment times. 


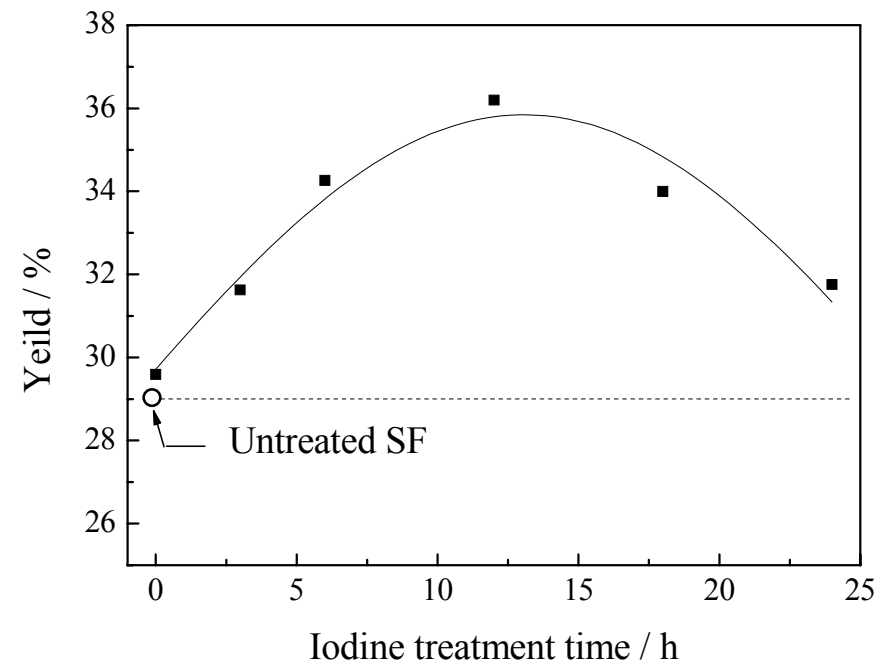

Fig. 5. Relationship between iodine treatment time and the yield of carbonized SF fiber according to multi step carbonization. The dotted line indicates the yield (29\%) of untreated SF fiber.

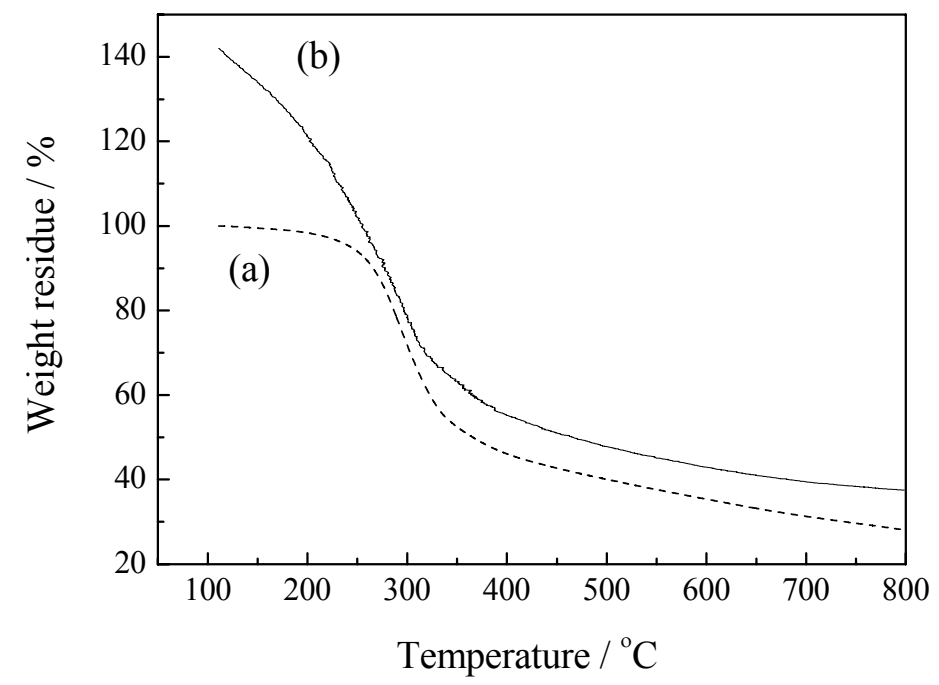

Fig. 6. TGA curves of SF fiber: (a) untreated specimen, measured at a heating rate of $5{ }^{\circ} \mathrm{C}$ in single step heating condition: (b) iodinated specimen, measured at $-0.001 \% / \mathrm{sec}$ weight reduction rate under CRC mode in dynamic condition. 


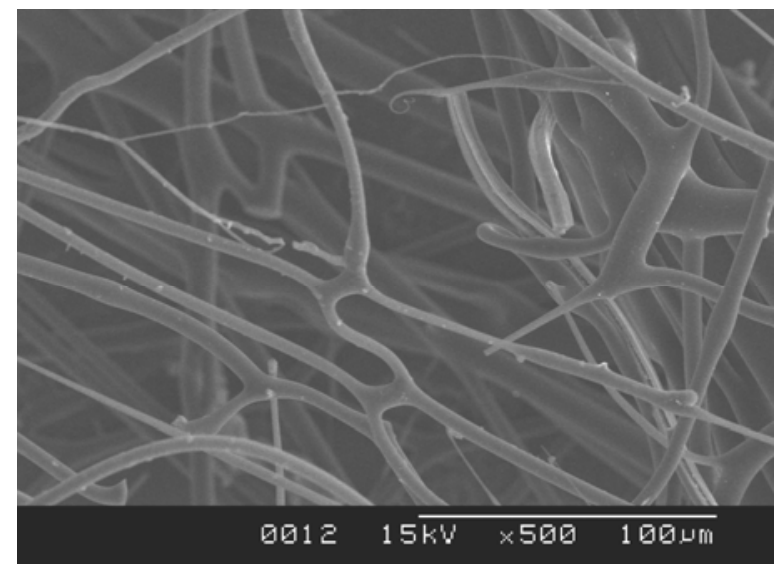

(a)

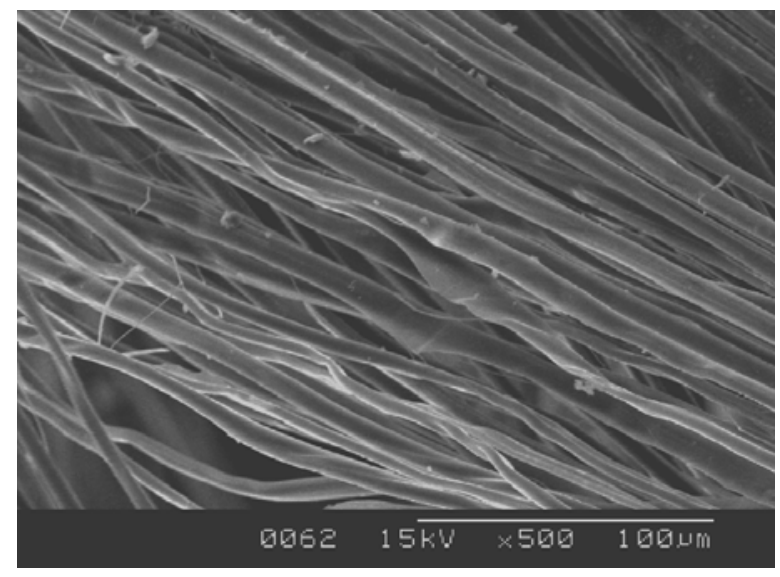

(b)

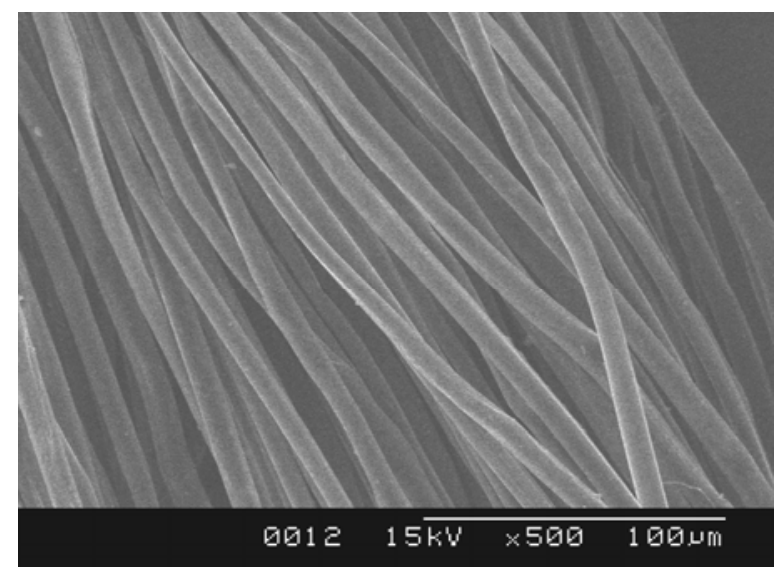

(c)

Fig. 7. Longitudinal SEM images of carbon fibers prepared from untreated and iodinated SF: (a) untreated specimen heated by single step carbonization; (b) untreated specimen heated by multi step carbonization; (c) iodinated specimen heated by multi step carbonization. 


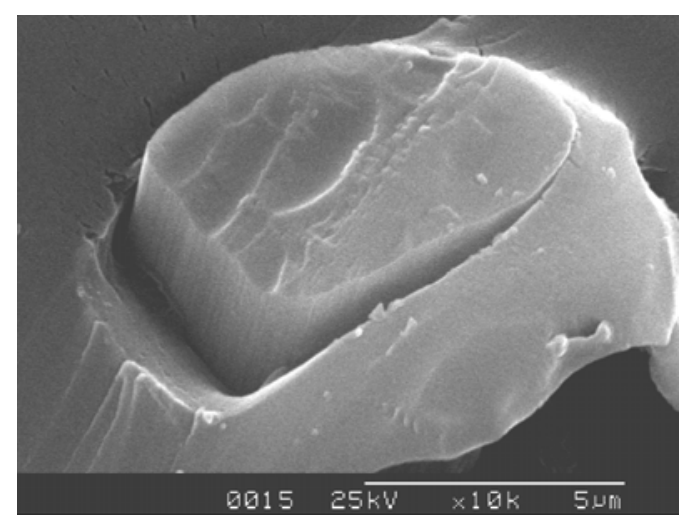

(a)

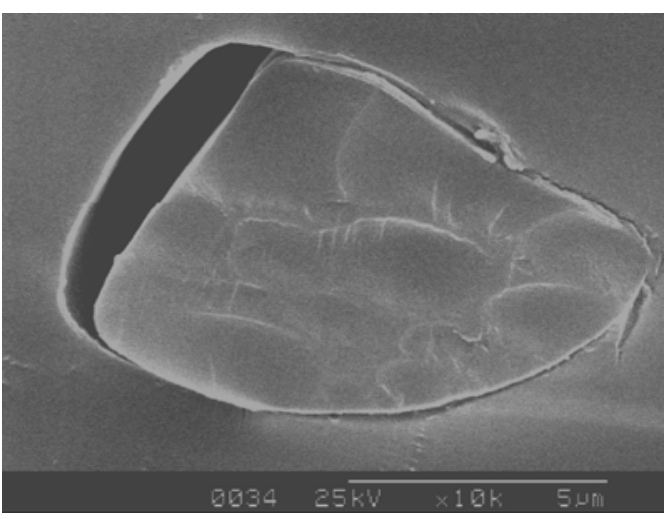

(b)

Fig. 8. Cross-sectional SEM images of carbon fibers prepared by multi step carbonization from untreated and iodinated SF: (a) untreated specimen, (b) iodinated specimen.

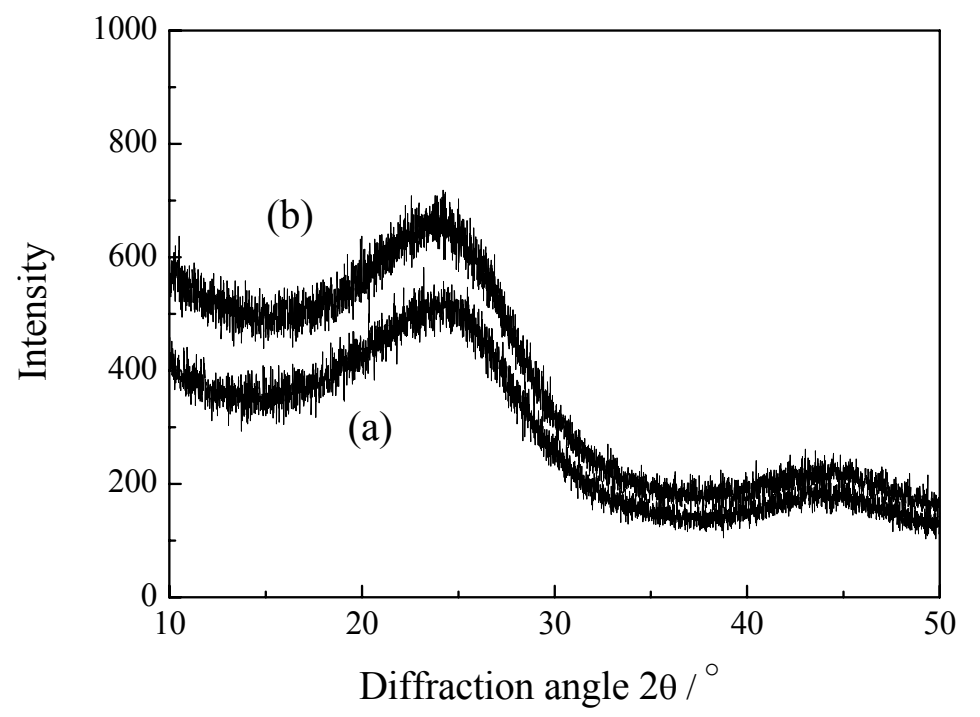

Fig. 9. Equatorial WAXD profiles of carbon fibers prepared by multi step carbonization from untreated and iodinated SF: (a) untreated specimen, (b) iodinated specimen. 


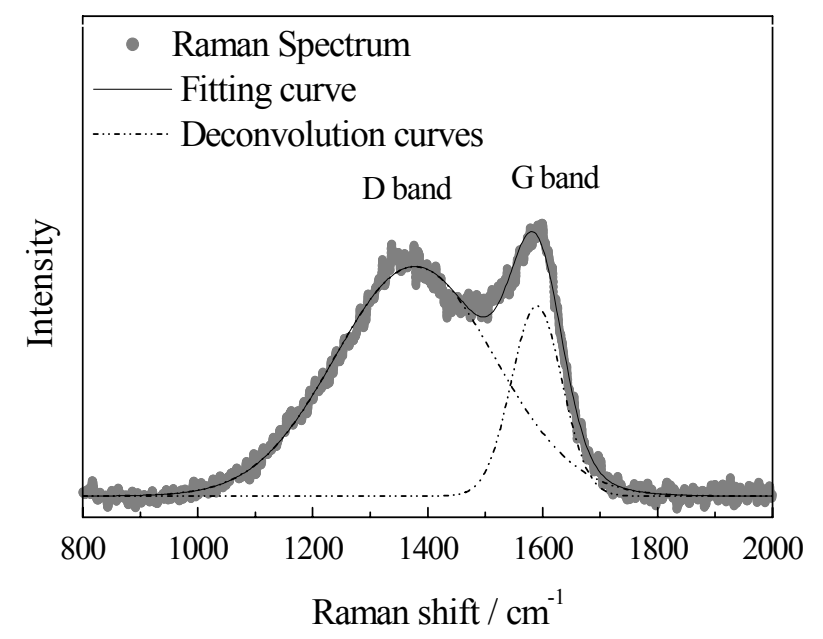

(a)

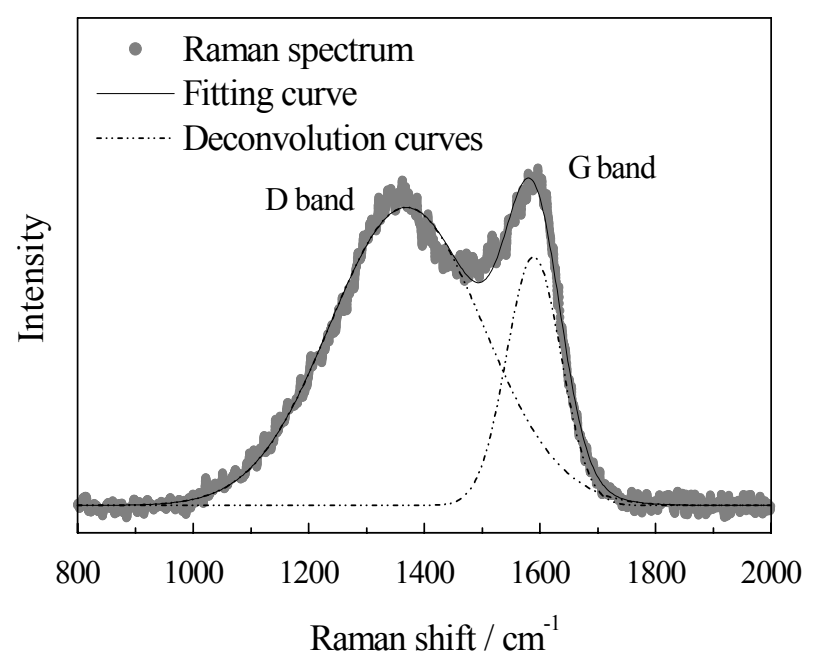

(b)

Fig. 10. Raman spectra of carbon fibers prepared by multi step carbonization from untreated and iodinated SF: (a) untreated specimen, (b) iodinated specimen. 

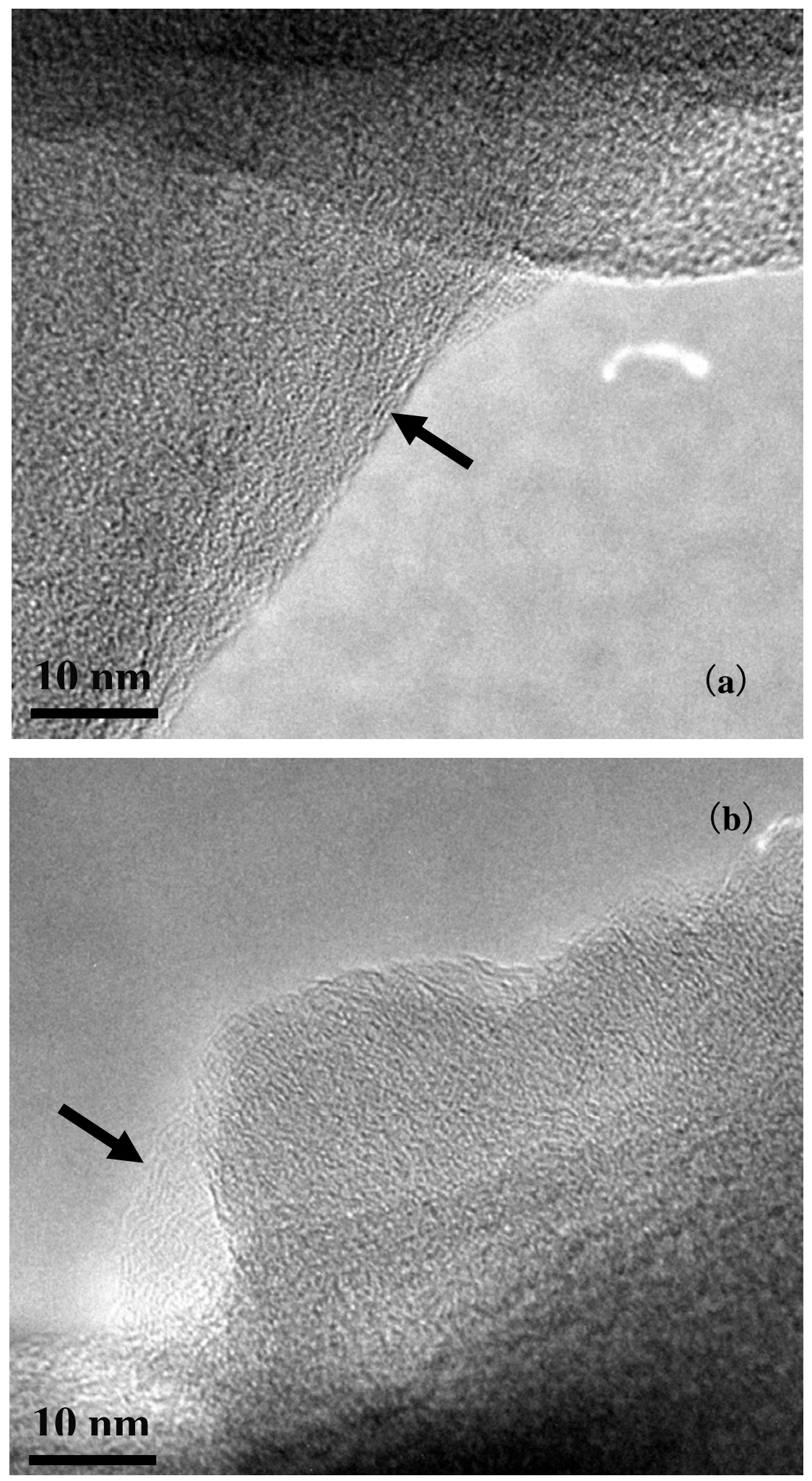

Fig. 11. TEM images of carbon fibers prepared by multi step carbonization from untreated and iodinated SF: (a) untreated specimen, (b) iodinated specimen. 


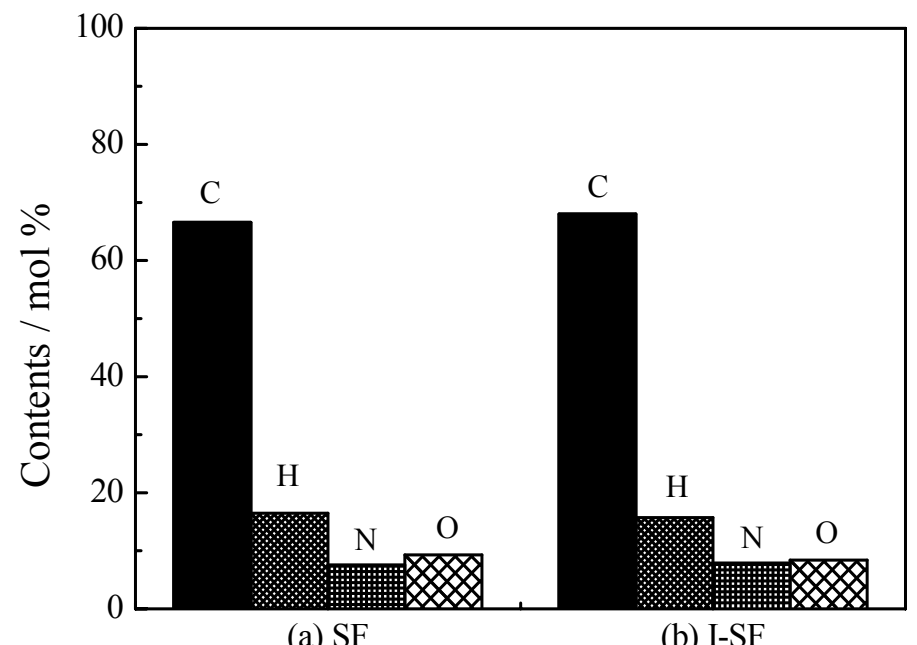

Fig. 12. Elemental composition of carbon fibers prepared by multi step carbonization from untreated and iodinated SF: (a) untreated specimen, (b) iodinated specimen. 

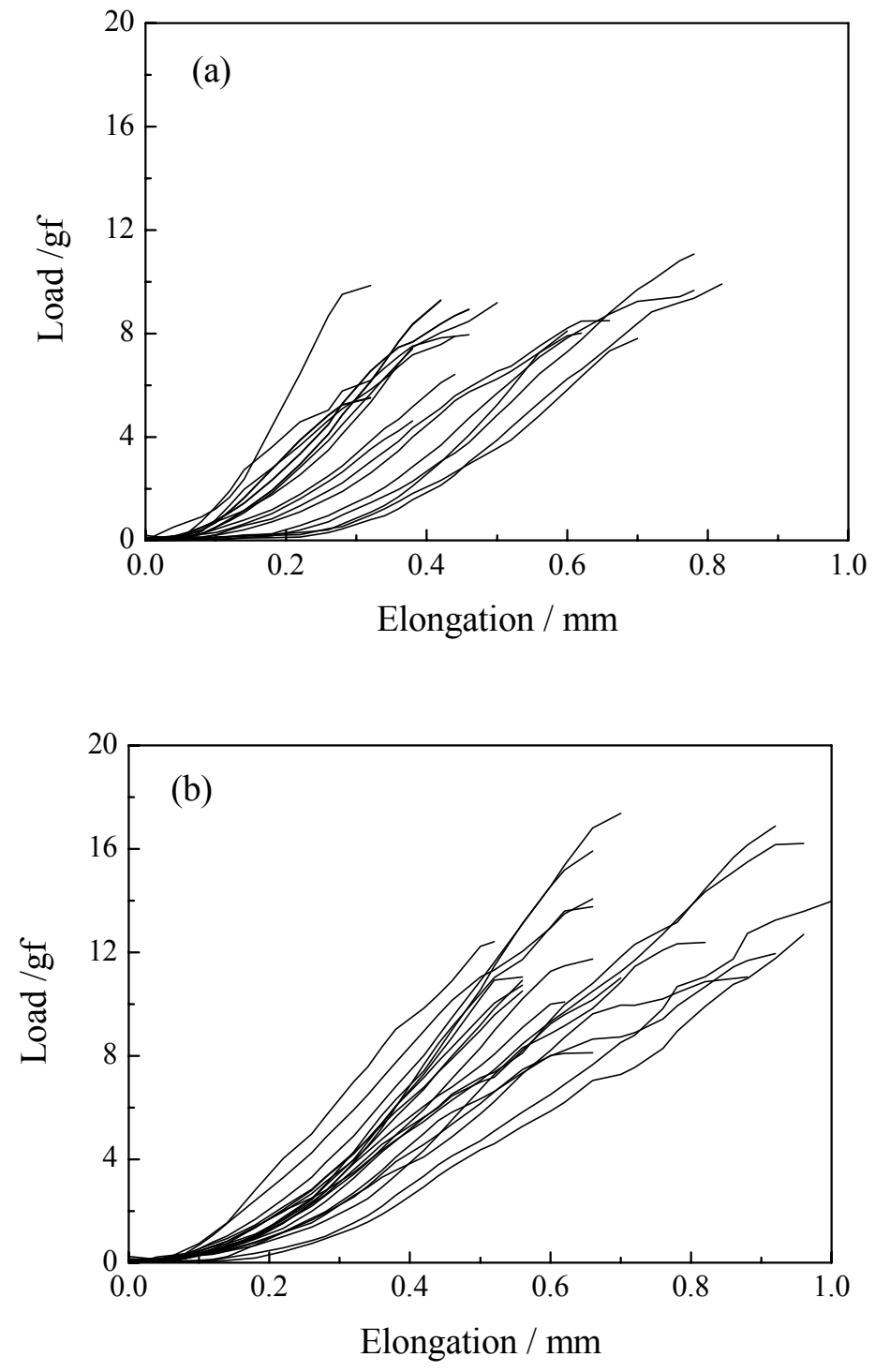

Fig. 13. Load-elongation curves of carbon fibers prepared by multi step carbonization from untreated and iodinated SF: (a) untreated specimen, (b) iodinated specimen. 


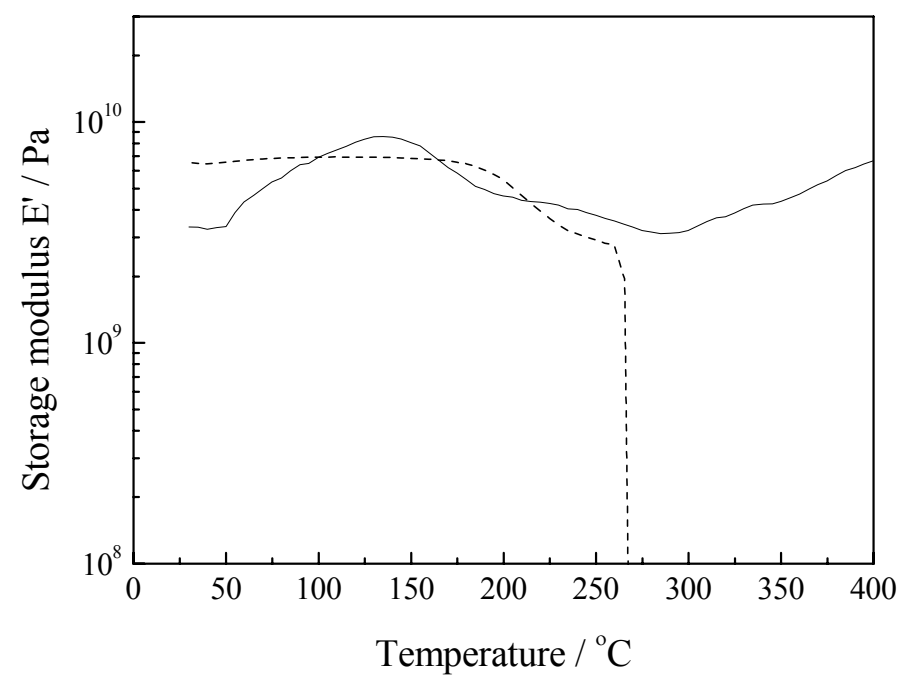

Fig. 14. Temperature dependence of storage modulus for untreated (dotted line) and iodinated (solid line) SF fiber.

Table 1. Structural parameters of carbon fibers prepared by multi step carbonization from untreated and iodinated SF determined by Raman spectroscopy

\begin{tabular}{|c|c|c|c|c|c|}
\hline \multirow{2}{*}{ Specimen } & \multicolumn{2}{|c|}{ G band } & \multicolumn{2}{c|}{ D band } & \multirow{2}{*}{$\mathrm{I}_{\mathrm{G}} / \mathrm{I}_{\mathrm{D}}$} \\
\cline { 2 - 5 } & $\begin{array}{c}\text { Peak Position } \\
\left(\mathrm{cm}^{-1}\right)\end{array}$ & $\begin{array}{c}\text { FWHM } \\
\left(\mathrm{cm}^{-1}\right)\end{array}$ & $\begin{array}{c}\text { Peak Position } \\
\left(\mathrm{cm}^{-1}\right)\end{array}$ & $\begin{array}{c}\text { FWHM } \\
\left(\mathrm{cm}^{-1}\right)\end{array}$ & \\
\hline Untreated SF & 1590 & 104 & 1377 & 326 & 0.53 \\
\hline Iodinated SF & 1589 & 111 & 1369 & 312 & 0.67 \\
\hline
\end{tabular}

